capacity of SR, although involvement of other factors such as differences in cell membrane (11) also have to be considered.

Total and tightly bound (intrinsic) Ca to SR per mg is greater in SHR than in NR, however, SR from NR seem to retain a greater amount of Ca against EGTA treatment in the presence of ATP, although the difference is minute (Table 1). Such is consistent with the fact that SR from NR has a greater ATP-dependent $\mathrm{Ca}^{++}$uptake capacity.

Acknowledgement: The authors express their thanks to Prof. S. Shibata of the Univ. of Hawaii for pertinent suggestions and discussion.

\title{
REFERENCES
}

1) OKamoto, K. AND Aoki, K.: Japan. Circulation J. 27, $282(1963)$; 2) Shibata, S., Kurahashi K. A.vo KuchiI, M.: J. Pharmacol. exp. Ther. 185, 406 (1973); 3) Spector, S., Fleisch, J.H., Maling, H.M. and Brodinfe, B.B.: Science 166, 1300 (1969); 4) Van Brfemen, C., Farinans, B.R., Geba, C.P., Wlytack, F. and Deth, R.: Phil. Trans. R. Soc. 265, 57 (1973); 5) Devine, C.E., Somlyo, S.V. And Somlyo, A.P.: Phil. Trans. R. Soc. 265, $17(1973)$; 6) FitzPatric, D.F., Landon, E.J., Debbas, G. and Huriwt 2 , L.; Science 176, 305 (1972); 7) Inesi, G. ANd WataNABE, S.: Archs Biochem. Biophys. 121, $665(1967)$; 8) AokI, K., IKEDA, N. YAMASHITA, K. AND Horta, K.: Japan. Heart J. 15, 475 (1974); 9) Lowry, O.H., Rosebrough, N.J., FARR, A.L. ANd RaNdall, R.J.: J. hiol. Chem. 193, 265 (1951); 10) Holloway, E.T. and Bohr, D.F.: Circulation Res. 33, 678 (1973); 11) Allan, W.J.: Circulation Res. 34 AND 35, Suppl. I, II, II-1 17 (1974)

\section{EFFECTS OF SUGAR AND INSULIN ON SODIUM BALANCE IN FASTED RATS}

\author{
Yasuko HAYASHI, Tsutomu NOHNO \\ and Yoshimichi MURAYAMA \\ Department of Pharmacology, Kawasaki Medical School, \\ Matsushima, Kurashiki-city 701-01, Japan
}

Accepted June 1, 1976

It has been reported that sodium loss into the urine increases during the first several days of fasling in normal and obese men (1-5) as well as rabbits (6), and that the increased sodium loss or the negative balance is reversed abruptly by the ingestion of glucose (1-5). In view of these observations, a hypothesis has been proposed that the antinatriuretic effect of carbohydrate refeeding may be attributed to the renal response to insulin, which was shown to cause antinatriuresis in man $(7,8)$ and dogs $(9)$. Recently, the authors observed in the clearance experinents that fasting for 1 to 5 days resulted in the natriuretic response of the rat kidney $(10,11)$. Therefore, the present study was undertaken to elucidate the effects of sugar refeeding and insulin administration on the negative sodium balance during fasting in unanesthetized rats.

Female Wistar rats weighing 200 to $314 \mathrm{~g}$ were given a regular diet (CLEA CE-2) 
containing $126 \mathrm{mEq} \mathrm{Na}$ and $221 \mathrm{mEq} \mathrm{K}$ per $\mathrm{kg}$ (the daily intake was $12.4 \pm 0.3 \mathrm{~g}$ ), and water ad libitum prior to experiment. Each rat was then housed in an individual metabolism cage (CLEA CT-10) well siliconized with high vacuum grease (Dow Corning), and given a low sodium diet (CLEA) containing $2.9 \mathrm{mEq} \mathrm{Na}$ and $125 \mathrm{mEq} \mathrm{K}$ per $\mathrm{kg}$ (the daily intake was $16.2-0.3 \mathrm{~g}$ ), and $15 \mathrm{mM} \mathrm{NaCl}$ solution which was provided throughout the experiment in order to maintain a constant sodium intake. After at least a 3-day period for equilibrating sodium balance, the animals were divided into two groups, each consisting of 9 rats, and three experimental procedures were adopted as follows: 1) one group was fasted for 4 to 5 days and the other was fed as a control: 2) one group was fasted for 2 days followed by 3 days of sugar refeeding (the daily intake was $12.7 \pm 0.8 \mathrm{~g}$ ), while the control group continued
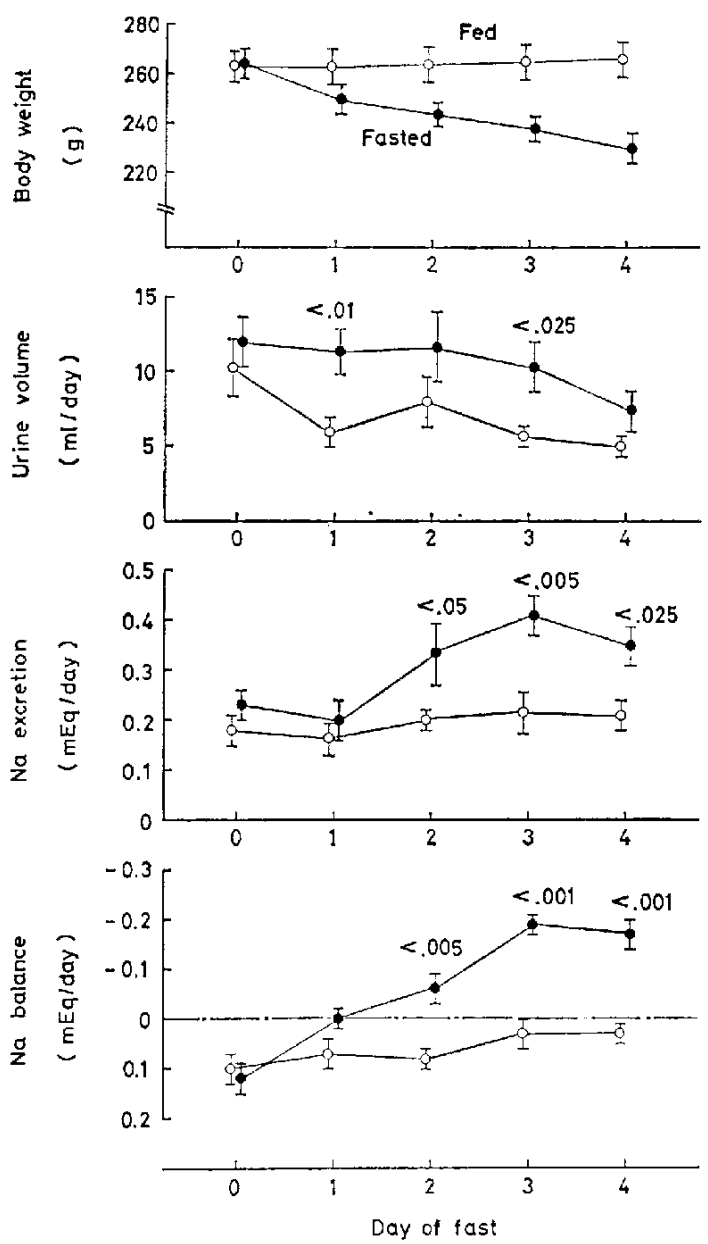

FIG. 1. Effect of fasting on sodium balance in the rats on a low sodium diet and 15 $\mathrm{mM} \mathrm{NaCl}$ solution. In experimental groups (O), food was withheld after a 3-day equilibration period and the values on the last day are expressed as day zero. In control groups (O), food was provided in the same manner as in the equilibration period. Sodium balanec was calculated by the subtraction of output from intake. Data are represented as the mean - standard errors $(n-9)$ together with the criteria of significant difference between two groups as indicated. 
to fast for 5 days; and 3) both groups were fasted for 5 days, of which animals in one group were given injections of lente insulin (Shimizu) for the last 3 days while the others were given a sham injection. A dose of 0.02 or $0.2 \mathrm{U} / 100 \mathrm{~g} \mathrm{B.W}$. per day of insulin was administered s.c. twice in a day. In the parallel experiment, additional rats were similarly treated and subjected to blood sampling from tail vein to test the effect of insulin on the plasma level of glucose.

In all experiments the following were measured daily: body weight, food and water intake, urine volume, urinary sodium and potassium output, and urinary osmotic pressure. Fecal electrolytes were not measured because of the negligible contents. Urinary concentrations of sodium and potassium were measured using a Hitachi flame photometer (Model 205), and urinary osmotic pressure was determined by freezing point depression using a Fiske osmometer (Model 230D). Glucose concentration in plasma was determined using a Glucose-Test Kit (Wako). The values given in the text are expressed as mean errors. The statistical significance of the data was calculated using Student's $t$-test.

Influence of fasting on sodium balance after equilibration period was examined according to the first procedure, and the representative results are illustrated in Fig. 1. In the fed group, sodium balance (intake minus output) was consistently positive throughout, whereas in the fasted group it shifted toward negative after food deprivation (from $119+28$ to -188 $\div 21 \mu \mathrm{Eq} /$ day on the third day of fast), and a significant difference between the mean values of the two groups was observed with a 2 - to 4-day fast $(\mathrm{p}<0.005)$. The sodium excretion of the fasted group was also significantly higher than that of the fed group in the same period $(\mathrm{p}<0.05)$. This is in agreement with the results obtained in the clearance experiments $(10,11)$, and also with the reports in humans (1-5). Urinary water output was gradually reduced in the fed group, while in the fasted group it remained almost unchanged until the second day of the fast and fell slowly thereafter.

The effect of sugar refeeding on the negative sodium balance in fasted rats was investigated with the second procedure. As shown in the upper part of Table 1, when sugar was available to the rats exhibiting a negative sodium balance in the fasting period $(-27-57$ $\therefore \mathrm{Eq} / \mathrm{day})$, the sodium balance returned to positive $(44 \pm 41 \mu \mathrm{Eq} /$ day $)$, though in the fasted control group, more negative values were evident on the same day $(-98+24 \mu \mathrm{Eq} /$ day $)$. This result supports the assumption that natriuresis in fasted subjects is ascribed to the alteration of carbohydrate metabolism, directly or indirectly. Since the plasma level of insulin, which was described as having antinatriuretic propertics (7-9), appeared to be affected by food withdrawal and subsequent carbohydrate refeeding, the participation of insulin in the negative sodium balance in fasted rats was studied using the third procedure. The negative sodium balance observed on the second day of fast $(-255+62 \mu \mathrm{Eq} / \mathrm{day})$ was intensified rather than suppressed with a daily injection of $0.2 \mathrm{U} / 100 \mathrm{~g} \mathrm{B.W}$. of insulin $(-305 \pm 55 \mu \mathrm{Eq} /$ day), as indicated in the middle part of Table 1 . The intensified value was significantly different from that of fasted rats $(93 \div 48 / 6 \mathrm{Eq} / \mathrm{day}, \mathrm{p}<0.025)$. The sodium excretion was also markedly clevated by exogenous insulin $(514 \ldots 65, \ldots \mathrm{Eq} /$ day as compared to $258 \pm 72$ " Eq/day in the control group). Since the dose of $0.2 \mathrm{U}$ of insulin used was pharmacologic 
TABLE 1. Effects of sugar refeeding and insulin injection on the negative sodium balance in fasted rats

\begin{tabular}{|c|c|c|c|c|c|c|c|}
\hline \multirow{3}{*}{ Experiment } & \multirow{3}{*}{$\begin{array}{l}\text { Day } \\
\text { of } \\
\text { fast }\end{array}$} & \multicolumn{4}{|c|}{ Output } & \multirow{2}{*}{\multicolumn{2}{|c|}{$\begin{array}{l}\text { Na balance } \\
(\mu \mathrm{Eq} / \text { day })\end{array}$}} \\
\hline & & \multicolumn{2}{|c|}{$\mathrm{H}_{2} \mathrm{O}(\mathrm{ml} / \mathrm{day})$} & \multicolumn{2}{|c|}{$\mathrm{Na}(\leadsto \mathrm{Eq} /$ day $)$} & & \\
\hline & & Cont. & Treat. & Cont. & Treat. & Cont. & Treat. \\
\hline \multirow[t]{3}{*}{ Sugar refeeding } & 0 & $7.1+0.9$ & $6.7 \pm 1.3$ & $133 \pm 26$ & $133 \div-24$ & $175 \div 24$ & $172 \pm 26$ \\
\hline & 2 & $7.1 \pm 1.6$ & $9.0 \pm 2.6$ & $160 \pm 36$ & $257 \pm 92$ & $25 \pm 17$ & $-27 \pm 57$ \\
\hline & 3 & $4.9 \pm 1.2$ & $8.9+3.6$ & $244 \div 28$ & $243 \div 48$ & $-98 \pm 24$ & $44 \pm 41^{* *}$ \\
\hline \multirow{3}{*}{$\begin{array}{l}\text { Insulin injection } \\
(0.2 \mathrm{U} / 100 \mathrm{~g} \text { B.W. })\end{array}$} & 0 & $5.3 \div 0.6$ & $6.2 \pm 0.8$ & $198 \pm 34$ & $211 \pm 30$ & $83 \pm 32$ & $111 \pm 36$ \\
\hline & 2 & $11.2 \div 2.3$ & $10.0+1.1$ & $405 \pm 63$ & $481+67$ & $-163 \pm 40$ & $-255 \pm 62$ \\
\hline & 3 & $6.3 \pm 2.2$ & $10.81: 1.9$ & $258 \div 72$ & $514\left\lfloor 65^{*}\right.$ & $-93 \pm 48$ & $-305 \pm 55^{*}$ \\
\hline \multirow{3}{*}{$\begin{array}{l}\text { Insulin injection } \\
(0.02 \mathrm{U} / 100 \mathrm{~g} \mathrm{B.W.})\end{array}$} & 0 & $5.5 \pm 0.3$ & $6.2 \pm 0.7$ & $173 \doteq 31$ & $151 \pm 25$ & $114=30$ & $143+33$ \\
\hline & 2 & $6.1 \pm 1.1$ & $5.9 \pm 2.2$ & $332 \doteq 32$ & $277 \doteq 56$ & $-160 \pm 23$ & $-102 \pm 37$ \\
\hline & 3 & $3.3+0.5$ & $6.2+2.6$ & $294+28$ & $358+59$ & $-198-28$ & $-200 \pm 30$ \\
\hline
\end{tabular}

Administration of sugar or insulin was begun on the third day of fast in one groun (Treat.), and control group (Cont.) was subjected to only fasting in the same way as in Fig. 1. Each value represents mean \pm standard error $(\mathrm{n}=9)$. Statistical singnificance is as follows: *, $\mathrm{P}<0.025$; **, $\mathrm{P}<0.01$ as compared to control.

and caused a significant fall in the plasma level of glucose in 1 to $6 \mathrm{hr}$ after administration $(76.8 \pm 3.6$ to $41.9+4.4 \mathrm{mg} / 100 \mathrm{ml}, \mathrm{p}<0.001)$, a lower dose of insulin $(0.02 \mathrm{U} / 100 \mathrm{~g} \mathrm{~B} . \mathrm{W}$. per day) in which the plasma glucose remained unchanged was employed. In this case, however, the sodium retaining effect of insulin was not observed (Table 1, lower part), and identical results were also obtained with the use of semilente insulin (Novo) monocomponent (data, not shown).

These results not merely rule out the proposal that the antinatriuretic effect of sugar refeeding may be attributed to the renal response to insulin (4), but contradict the reports that insulin has a sodium retaining effect in man $(7,8)$ and isolated dog kidney (9). Since the increment in sodium excretion by exogenous insulin in a higher dose was accompanied with a decrease in plasma glucose, the apparent natriuretic effect of insulin may be due to the resulting deficiency of energy substrates such as glucose or free fatty acids (12) and /or the decrease in sodium reabsorption coupled with glucose transport at the proximal tubule. Even in a lower dose, however, insulin administration did not restore the natriuresis in fasted rats without observable change in plasma glucose. Therefore, the possibility that insulin may be responsible for the negative sodium balance during fasting and its recovery by sugar refecding is ruled out, at least, in rats. To clarify the mechanism of fasting-induced natriuresis, further investigations are underway in our laboratory.

Acknowledgements: Thanks are due to Miss A. Segawa for generously providing technical assistance.

\section{REFERENCES}

1) Bloom, W.L.: Archs intern. Med. 109, 26 (1962); 2) Katz, A.I., Hollingsworili, D.R. 
and Epstein, F.H.: $J$. Lab. clin. Med. 72, 93 (1968); 3) VeVfrrrants, E. And Arky, R.A.: $J$. clin. Endocr. Mctab. 29, 55 (1969); 4) Kolanowski, J., Pizarro, M.A., de Gasparo, M., Desmecite, P., Harvengt, C. And Crabbé, J.: Furop. J. clin. Invest. 1, 25 (1970); 5) Schloeder, F.X. And Stineratugh, B.I.: Metabolism 19, 1119 (1970); 6) Cizek, L.J.: Am. J. Physiol. 201, 557 (1961); 7) Miller, J.H. and Bogdanoff, N.D.: J. appl. Physiol. 6, 509 (1954); 8) DeFronzo, R.A., CoOke, C.R., Animkes, R., Faloona, G.R. and Davis, P.J.: J. clin. Invest. 55, 845 (1975); 9) Nizet, A., Lefebvre, P. and Crabbí, J. : Pfiügers Arch. 323, 11 (1971); 10) Murayama, Y. and Sakai, F.: Japan. J. Pharmacol. 25, 475 (1975); 11) Murayama, Y., Watanabe, S. AND HAYASHI, Y.: Folia pharmacol. japon. 72, 229 (1976) (in Japanese); 12) Trimble, M.E. AND Bowman, R.H.: Am. J. Physiol. 225, 1057 (1973)

\title{
SPECIFICITY OF MUSCLE RESPONSE OF THE JAPANESE MEDICAL LEECH TO ACETYLCHOLINE
}

\author{
Mitsuhiro NAGATA and Ken KADOTA* \\ Department of Pharmacology, Kansai Medical School, Moriguchi, Osaka 570 , \\ and ${ }^{*}$ Department of Pharmacology, Osak a University Medical School, \\ Kita-ku, Osaka 530, Japan
}

Accepted June 7, 1976

In a previous papaer (1), we reported a promising bioassay procedure for acetylcholine (ACh) using the Japanese medical leech, a material hitherto regarded as of no practical use (2). A thin dorsal muscle strip of roughly $0.4 \times 15 \mathrm{~mm}$ was mounted in a microbath $(0.2$ $\mathrm{ml}$ in volume) (3-5), and the tensions developed by the muscle piece were recorded via a UL-type tension transducer with a relatively stiff spring stretching to $0.2 \mathrm{~mm} / \mathrm{g}$ in weight and an AS-3A pen recorder (Shinko Tsushin Co.). With this system, it was shown that the muscle strip contracted in response to ACh levels ranging from $1 \times 10^{-8}$ to as low as $1 \times 10^{-20} \mathrm{~g} / \mathrm{ml}$. The effect of $\mathrm{ACh}$ was seen in less than $1 \mathrm{~min}$ and washed out within $5 \mathrm{~min}$ to leave a constant base line. Such was attributed to either the thin muscle piece which was easy to wash, or to a springloaded lever of the tension transducer ( 3 , 6 ), or to both. The resulting doseresponse curve was linear to the graded small steps in $\mathrm{ACh}$ concentration.

The present study was designed to help clarify the muscle specificity to $\mathrm{ACh}$ and its block by a cholinergic antagonist in the muscle response of the medical leech here, the Hirudo nipponia Whitman (7). The experiments were carried out at a room temperature of $18-23^{\circ} \mathrm{C}$ through

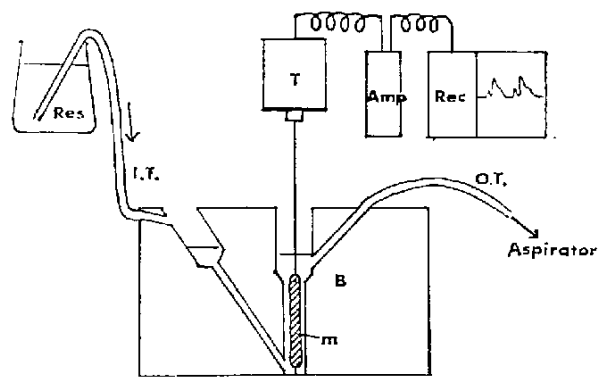

Fio. 1. Assembly of apparatuses for detecting changes in tension in a leech thir muscle strip. Amp $=$ amplifier. $B=$ Whittaker"s microbath. I.T. - inlet tube to the bath. $m-$ muscle strip. O.T. -- outlet tube. Rec. -recorder. Res. - reservoir. $T=$ tension transducer. 